friend Mr. Gardner of his first successful vaccination. Pasteur had a sleepless night of anxiety when he had completed his first inoculations for rabies on a human being. Lister, a member of the Society of Friends, could write, "I don't think any case ever excited me so much", in referring to his first use of antiseptic ligatures. Graham Bell and Edison were delighted with the telephone and the phonograph respectively. Lord Kelvin, having devised a delicate electrical instrument, would have it brought to his drawing-room mantelpiece, so that he might exult over it at leisure. So the story continues. The joy of the creative intellect, whether in art, literature or science, is one of the most exalted human emotions.

\section{Drops and Splashes}

Two public lectures under the auspices of the British Association were given at Preston (September 16) and at Rochdale (September 17) by Prof. Allan Ferguson, who took as his subject "Splashes and What They Teach". The lectures dealt with the phenomena attendant on the formation and separation of a drop of water at the end of a vertical tube, the splash of a drop of liquid falling into a liquid, of a solid sphere falling into a liquid and of a drop of mercury falling on to a horizontal sheet of glass. As is well known, experiments were carried out by Worthington some forty years ago in order to elucidate some of these happenings. Photographic technique was then very primitive, and Worthington's experiments were carried out under difficult conditions. Recently a high-speed camera has been developed, in which the film is drawn continuously through the camera at a speed of about thirty miles an hour. A prism rotating rapidly about a horizontal axis is placed between the lens system of the camera and the film, and throws a picture of the object downwards on the film, so that, for a fraction of a second, the image is stationary relative to the film. In this way it becomes possible to take pictures at the rate of 2,000 a second, and therefore, by running them through a projector at the rate of 20 a second, to alter the time-scale in the ratio of a hundred to one. The films so taken corroborate in a remarkable manner the results obtained by Worthington's method of taking separate photographs of drops, each at a different stage of its fall.

\section{Caucasian Studies}

To remedy the neglect of a field in which the Russian literature, with a virtual monopoly created by circumstance, can do less than justice, a society has been founded in England for the promotion of Georgian and Caucasian studies. The promoters include Sir Oliver Wardrop and Mr. W. E. D. Allen, who are among the foremost authorities on Georgia in the West. Sir Denison Ross is the Society's first president. The Society will publish a journal under the title Georgica, of which the first part has already appeared. Its contents, for most of which natives of Georgia, recognized as authorities, are responsible, indicate that breadth of interest, combined with sound scholarship, will be the aim of its promoters. Georgica will also endeavour to keep its readers abreast of current developments in Caucasian studies not otherwise readily accessible. As preliminary matter, Sir Denison Ross contributes an introductory note explaining the objects and methods of the new society, and Mr. W. E. D. Allen reviews the present state of Caucasian studies. Among the remaining papers are a discussion of Georgian chronology by Prof. Taqaishvili, an examination of the Asianic element in Georgian paganism by Prof. M. Tseretelli (seo p. 512 of this issue of Nature), a census of Georgian manuscripts in England, of which there are three important collections, by the Archimandrite Peradze, and an account of the Holy Lance of Echmiadzin by Mr. F. J. Baddeley, who considers that it is identical with the lance discovered in the siege of Antioch in 1098. Dr. A. Gugushvili adds a valuable, if tentative, system of Georgian phonetics, which, it may be hoped, will lead to further discussion. The honorary secretary of the Georgian Society is Dr. A. Gugushvili, to whom inquiries should be addressed at Commonwood House, Chipperfield, Herts.

\section{Exhibition of Photography}

THE eighty-first Annual Exhibition of International Photography by the Royal Photographic Society was opened on September 11. It will remain open daily (Sundays excepted) from 10 a.m. until 9 p.m. (Tuesdays and Fridays excepted-lecture evenings-when it will be closed at 6 p.m.) until Saturday, October 10. Pictorial photography occupies the principal galleries and, as usual, has attracted exhibitors from all over the world. Among the scientific exhibits are two infra-red photographs taken by A. W. Stevens and O. A. Anderson from about 69,780 feet above the ground over Central South Dakota on November 11, 1935. One of these is a vertical photograph, the other lateral. The latter is said to be the first photograph to show the division between the troposphere and the stratosphere. The horizon, 330 miles away from the camera, is clearly arched. The trade sections, though not extensive, are well worth inspection. The emphasis among apparatus is upon the miniature cameras. Instructional exhibits include explanations of the working of the Pola screens and of the Kodachrome process, the effects of varying the filter in making photomicrographs of stained sections and the troubles that may arise through mishandling photographic materials.

\section{Smoke Abatement Exhibition at the Science Museum}

AN exhibition on the abatement of smoke will be opened at the Science Museum, South Kensington, by the Minister of Health, the Right Hon. Sir Kingsley Wood, M.P., on October 1, and will remain open until October 31. It has been arranged by the National Smoke Abatement Society (by permission of the director of the Museum, Colonel E. E. B. Mackintosh), with the co-operation of interested Government departments and industrial associations. Models and other exhibits demonstrating the efficient combustion of coal in steam-raising and other industrial operations will be shown, and other sections 